\title{
Intelligent Energy Buildings based on RES and Nanotechnology
}

\author{
S. Kaplanis* and E. Kaplani \\ R.E.S. Laboratory, Mechanical Engineering Dept., Technological Educational Institute of Western Greece \\ M. Alexandrou 1, Koukouli 26 334, Patra, Greece \\ *Correspondence: kaplanis@teipat.gr
}

\begin{abstract}
The paper presents the design features, the energy modelling and optical performance details of two pilot Intelligent Energy Buildings, (IEB). Both are evolution of the Zero Energy Building (ZEB) concept. RES innovations backed up by signal processing, simulation models and ICT tools were embedded into the building structures in order to implement a new predictive energy management concept. In addition, nano-coatings, produced by TiO2 and ITO nanoparticles, were deposited on the IEB structural elements and especially on the window panes and the PV glass covers. They exhibited promising SSP values which lowered the cooling loads and increased the PV modules yield. Both pilot IEB units were equipped with an on-line dynamic hourly solar radiation prediction model, implemented by sensors and the related software to manage effectively the energy source, the loads and the storage or the backup system. The IEB energy sources covered the thermal loads via a south façade embedded in the wall and a solar roof which consists of a specially designed solar collector type, while a PV generator is part of the solar roof, like a compact BIPV in hybrid configuration to a small wind turbine.
\end{abstract}

Keywords: Intelligent energy building, Stochastic sizing, SSP, Nanocoatings, Solar radiation prediction PACS: 88,89

\section{INTRODUCTION}

The RES technologies gained importance by the time since more than 40 years and offered themselves to new building architectures. The aim was the exploitation of the solar energy towards passive solar designs and bioclimatic buildings meeting the comfort conditions,[1-2]. Their natural evolution was the (net) Zero Energy Buildings,(n)ZEB, or zero emission buildings,[3-10], whose characteristic was the integration of RES everdeveloping technologies into the building structures, sometimes associated to conventional technologies, too. During the last decade nano-technology products are introduced to make part of the surface and the structural elements. Also, ICT tools associated to solar energy/radiation and sophisticated solar/energy radiation modelling make up the contemporary IEB units to satisfy energy cost-effective solutions, zero energy or even positive energy buildings. These gave a boost to the concept of the Intelligent Energy Building [9,11,12]. In many cases, the IEB was a reengineering product of the ZEB. This paper deals with such a case presenting two pilot IEB designs with advanced in-built properties. Their main feature is the artificially granted ability of the building to predict the hourly patterns of the daily global solar radiation, ex ante, since the early morning hours of a day [12]. The other main feature, comes through Spectral Selective Properties, (SSP), provided by nano-coatings, produced by ITO and TiO2 nanoparticles, on the building structural elements, $[13,14]$. All these above, made the IEB test units to achieve energy performance control optimization based on solar radiation prediction, stochastic PV and solar collector sizing and nano-material which affect thermal \& cooling loads.

\section{CONCEPT AND DESIGN OF TWO IEB TEST CELLS}

Two pilot Intelligent Energy Buildings (IEB) are studied as a reengineering output of Zero Energy Buildings (ZEB), Figures 1a,b,c. The design principles, the energy modeling and operational details of both IEB units are outlined in this paper. RES technologies, solar radiation simulation models accompanied by special software, on-line management and ICT tools, new material and nano-coatings were all embedded into their structures. The result was the cost-effective IEB units which meet the criteria to cover the thermal and power loads with the minimum installed PV peak power. The PV sizing followed a stochastic process, according to the preset load profiles and priority criteria related to load time shifting. Thus, a further reduction in the peak power was achieved [15]. 
The first IEB unit is equipped with a $110 \mathrm{Wp} \mathrm{PV}$ array and $2 \mathrm{~m}^{2}$ flat plate solar collector type of construction as a south façade inbuilt into the wall and $1 \mathrm{~m}^{2}$ flat plate collector type making part of the roof, as shown in Fig.1a. A $50 \mathrm{~W}$ wind turbine in a hybrid connection to the PV contributed in meeting the IEB test cell power loads.

Fig.1a shows an embedded to south wall innovative construction to operate as a solar collector type construction providing warm water to the under-floor heating system. Also, a solar chimney at the top end of the solar roof, a pyranometer and indoor-outdoor temperature sensors, as well as glass windows nano-coated with ITO and $\mathrm{TiO}_{2}$ nano particles through a spray technique developed for this project, provide intelligent features in this IEB unit especially as it concerns their energy performance and management.

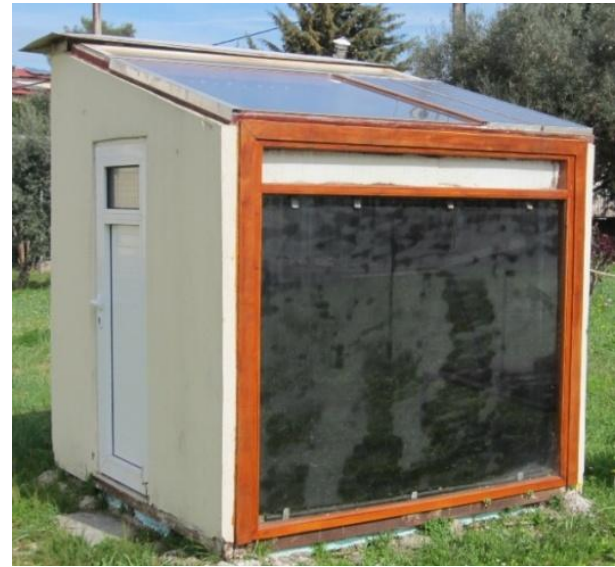

(a)

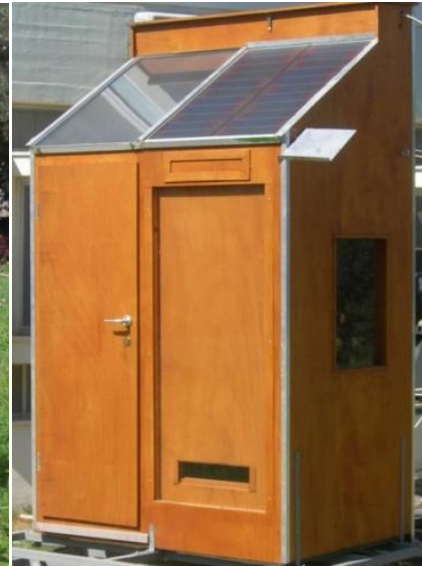

(b)

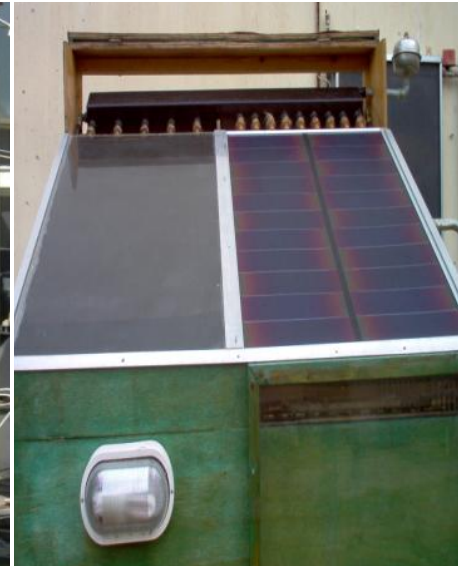

(c)

FIGURE 1. (a) The first IEB test cell with inbuilt south façade and solar roof. The pyranometer, provides signals for solar radiation prediction, (b) the second IEB pilot unit with a PV/T roof combined with the solar collector part, (c) another version of the same IEB unit where tubes with eco-Freon are attached in the PV back surface and in the solar collector construction.

The second IEB test cell unit has a slight different design. It is powered by a compact solar roof. Part of the roof is an embedded PV/T, based on an a-Si module of $50 \mathrm{Wp}$. Tubes filled with eco-Freon were in a very good conduction bond to the PV panel. Freon vapor produced travels upwards to the end of the tubes, whose ends are inside a heat exchanger at the back of the roof, see Fig. $1 \mathrm{~b}, \mathrm{c}$, to provide hot water around $40-45^{\circ} \mathrm{C}$ suitable for under floor heating. Cooled vapor flows down the tubes in liquid form, in a two phase flow. The rest part of the roof is a solar collector construction operating with eco-Freon too as cooling agent without the need of any pump circulator. It provides domestic hot water and under floor space heating. The south façade has a narrow air space of $5 \mathrm{~cm}$ confined by a glass panel and a brown/green wall, Figs.1b,c. The air is self-pumped in/out of the building based on the thermo-siphon effect, according to the indoor thermal requirements, e.g. winter, spring, summer, etc.

Another version of this IEB unit construction with the same technical features, as the one of Fig.1b, had a greenish color for optical euphoria in the south façade. The south façade has a narrow air space confined by a glass panel and a brown/green wall.

A combined solar thermal and power roof was designed, where a special construction of a flat plate solar collector type roof, side by side to PV modules served both as power and thermal energy provider and as a roof, too to lower costs. Both pilot IEB units were equipped with a dynamic hourly global solar radiation prediction model,[12], implemented via temperature sensors, a pyranometer, a digital flow meter and signal processing in order to operate on a predictive IEB management based on the Energy Balance Equation:

Energy Provider - Loads $=$ Storage $/$ back up system

$$
Q u, p r^{-} \sum Q_{L i}+Q_{b}=Q_{s t}
$$

where, Qu,pr represents the predicted useful energy to be delivered on an hourly basis in a day, $\Sigma \mathrm{QLi}$ represents the sum of the Loads which are associated to a priority coefficient each one, eq.(2), for the implementation of the load time shift and $\mathrm{Q}_{\mathrm{b}}, \mathrm{Q}_{\mathrm{st}}$ are the amount of energy provided by the back up source and the stored energy respectively. 


$$
Q_{L}(W h / \text { day })=Q_{L, c r i t}+e_{1} Q_{L, 1}+e_{2} Q_{L, 2}+\ldots
$$

The intelligent tool no1.

A special software developed may predicted the hourly patterns, I(h;n), of the daily global solar radiation [12] based on the early morning pyranometer measurements in a day, $n$. The hourly solar radiation prediction, as in eq.(3), enables the estimation in a day of the power to be delivered, as analyzed in [14,15].

$$
I_{p r}\left(h_{3} ; n_{j}\right)=I_{a v}\left(h_{3} ; n_{j}\right)+R \cdot \sigma_{I\left(h_{3} ; n_{j}\right)}+\frac{1}{2} \cdot\left(t_{2} \cdot \sigma_{I\left(h_{2} ; n_{j}\right)}-t_{1} \cdot \sigma_{I\left(h_{1} ; n_{j}\right)}\right) \cdot R_{1}
$$

$\sigma \mathrm{I}(\mathrm{h} 2 ; \mathrm{nj})$ and $\sigma \mathrm{I}(\mathrm{h} 3 ; \mathrm{nj})$ are the s.d. of the measured $\mathrm{I}(\mathrm{h} ; \mathrm{nj})$ values at hours $\mathrm{h} 2$ and $\mathrm{h} 3$, respectively, in the day nj, as obtained from the databank. The expression above includes two stochastic terms, one which stands for the stochastic fluctuations at hour $\mathrm{h} 3$, and a second term to stand for the rate of change of the $\mathrm{I}(\mathrm{h} ; \mathrm{nj})$, within the time interval $[\mathrm{h} 1, \mathrm{~h} 2] . \mathrm{R}$ is a random number Gaussianly distributed, $(0,1)$, with a mean equal to 0 and a standard deviation equal to 1 . Accepted values of $\mathrm{R}$, according to this model, should lie within the interval [t $1 \pm 1]$, where $\mathrm{t} 1$ is determined by eq.(4) below,

$$
t_{2}=\frac{\mathrm{I}_{\text {meas }}\left(\mathrm{h}_{2} ; \mathrm{n}_{\mathrm{j}}\right)-\mathrm{I}_{\mathrm{av}}\left(\mathrm{h}_{2} ; \mathrm{n}_{\mathrm{j}}\right)}{\sigma_{\mathrm{I}\left(h_{2} ; n_{j}\right)}}
$$

$I_{a v}\left(h ; n_{j}\right)$ represents the average of hourly data for the day $n_{j}$ over a number of years as obtained from a databank.

$\mathrm{R} 1$ is randomly distributed according to a Gaussian p.d.f. $(0,1)$. The term $\left(\mathrm{t} 2 * \sigma_{\mathrm{I}}(\mathrm{h} 2 ; \mathrm{nj})-\mathrm{t} 1 \sigma_{\mathrm{I}}(\mathrm{h} 1 ; \mathrm{nj})\right) * \mathrm{R} 1$ stands for the contribution to the $\mathrm{I}(\mathrm{h} ; \mathrm{nj})$ prediction by its rate of change during the 2 previous hours. After the estimation of the intensity of the solar radiation, the algorithm continues to predict the next hour and so on.

This tool contributes to a cost-effective sizing to cope with the required power and thermal load profiles in a reliable way based on the preset Loss Load Probability concept [15]. The prediction of the power to be delivered by the PV generator combined by the prediction of the heat to be stored during a day constitute a dynamic property of this IEB construction. The PV peak power installed using the stochastic sizing is about 20-25\% less compared with that determined by conventional sizing methods, as described in [14]. On the other hand, the power prediction permits the effective shift of the loads to another day when excess power and heat will be predicted to happen since the early hours of a day. Thus, instead of burning the excess energy it is used to meet the shifted loads. This dynamic behavior leads to an additional decrease in the installed PV peak power by $10 \%$ compared to the simple PV sizing methodologies. Fig.2 shows the comparison between the average global solar radiation profile against a real measured one and the predicted by the software developed. There are cases where the average is much different than the real and the predicted. These are the cases of high importance in the loads time shift scenario.

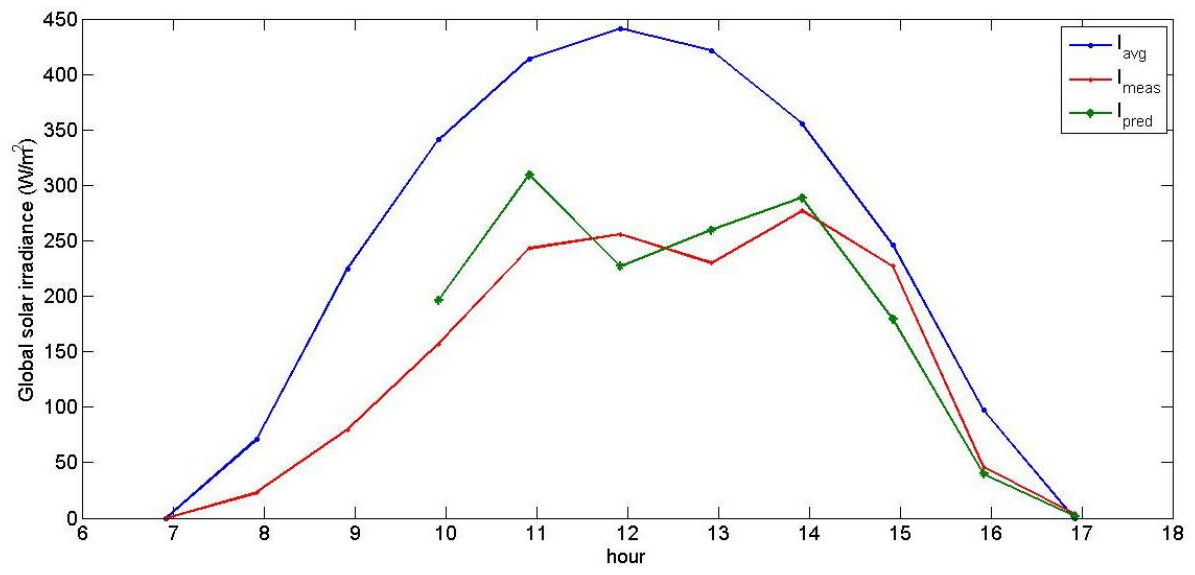

FIGURE 2. Global solar radiation predicted profile for the 17th January, in Patra, Greece, compared to the real hourly profile as measured and the average one from a 5 years databank. 
The 2nd intelligent tool

The sizing of both PV generator and the flat plate collector system embedded on the solar roof and in the façade is based on a stochastic model, by the following equations, as outlined in [15 ].

$$
\begin{aligned}
& E_{P V}=P_{m, \mathrm{cor}} \cdot P S H \cdot R \\
& P_{m, \mathrm{cor}}=Q_{L} \cdot\left(1+\sqrt{d} \cdot 2 \cdot \sigma_{H} / H_{m}\right) /\left(P S H_{m} \cdot \bar{R} \cdot \prod_{\iota} \varepsilon_{l}\right)
\end{aligned}
$$

where, $\mathrm{Q}_{\mathrm{L}}=\Sigma \mathrm{Q}_{\mathrm{L}}, \mathrm{i}$ is the daily load in (Wh/day),

$\mathrm{PSH}$, is the Peak Solar Hour (h/day), either taken as an average value from the database or predicted, as said above.

$\mathrm{P}_{\mathrm{m}, \mathrm{cor}}$ is a corrected peak power due to solar radiation fluctuations. $\sigma_{\mathrm{H}}$ is the standard deviation of the daily global solar radiation on the horizontal and $\mathrm{H}_{\mathrm{m}}$ is the mean daily value as estimated using the databank. $\mathrm{R}$ is the solar radiation conversion coefficient from the horizontal to the inclined plane, either for the day the PV operation is studied, see eq.(5). It is either the daily value estimated through equations based on that day's solar irradiation and the clearness index coefficient or it is the mean value for that day, see eq.(6), based on past years values of the solar radiation in that site, as estimated in [14].

$d$ is the number of the days the PV-plant is energy independent under a 95\% confidence level. $d$, in the stochastic model of PV sizing, used in this case, was not preset but it is a parameter to be determined through the loss load probability simulation process.

Пвi, is the product of the DC power transfer coefficients from the PV generator till the DC/AC unit. They have to take into account the daily and night coefficients and their values, as it is mostly important.

Using this methodology, the minimum values of the PV generator peak power, the energy storage capacity and the adequate solar collectors surface are determined for a preset Loss Load Probability. The decrease in the sizing results reached for the local climate, $\varphi=38 \mathrm{~N}, 20-25 \%$ compared to the classical sizing methods

Further minimization of the PV generator peak power and the storage system was obtained by loads time shift, too.

The combination of the tools no1 \& 2 decrease even further the PV installed peak power to about 30-35\% compared to other classical methodologies, described in [14]. In general, the IEB management system controls the energy provider/sources-loads-storage, where the solar radiation is simulated and predicted on an hourly basis, Figure 2. On the other hand, the loads were managed - with on/off mode or time shift- by distance, too, according to the prediction of the energy to be harvested during the day.

The intelligent tool no3.

The regular check of the PV generator against power degradation effects is essential in order to protect the system against unwanted power reduction due to external agents, which could lead to a faster PV aging process [16]. This is achieved through diagnostic techniques which include I-V curve monitoring and IR thermography, see Fig. 3. This tool should be further associated to a self-cleaning property of the nano-coated surfaces, to be described in the next section.

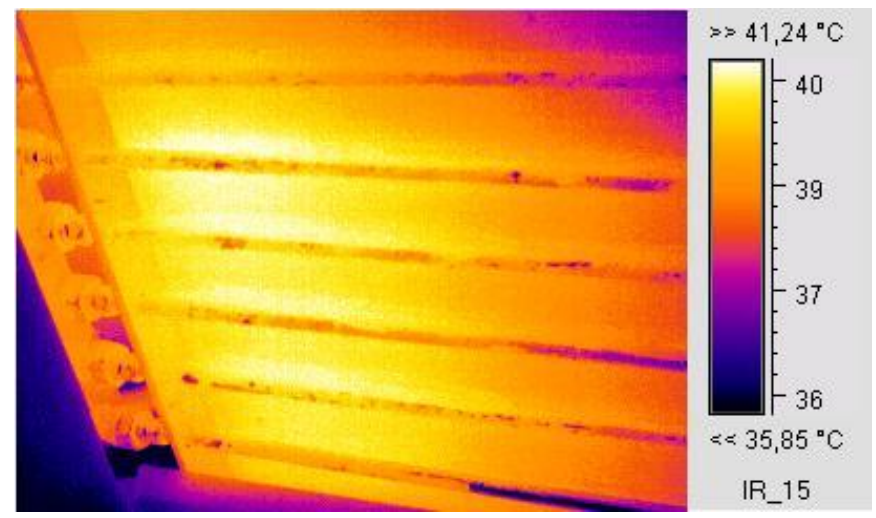

FIGURE 3. IR thermography of PV/T. 


\section{Introduction of nanocoatings to IEB units}

Nanotechnology developments were also introduced in these IEB structures. Nanocoatings based on $\mathrm{TiO}_{2}$ and $\mathrm{SiO}_{2}$ nanoparticles diluted into an organic binder were deposited onto the IEB window glasses and the PV glasses using a spray technique for massive coating. The spectral transmittance of the nanocoated glass as measured is shown in Fig. 4. The contribution of those nanocoatings, of about $200 \mathrm{~nm}$ thickness, showed an increase of $1.5 \%$ in total in the transmission coefficient in the VIS part of the solar spectrum, in parallel to a decrease in the reflectance, as compared with the measurements of a reference glass.

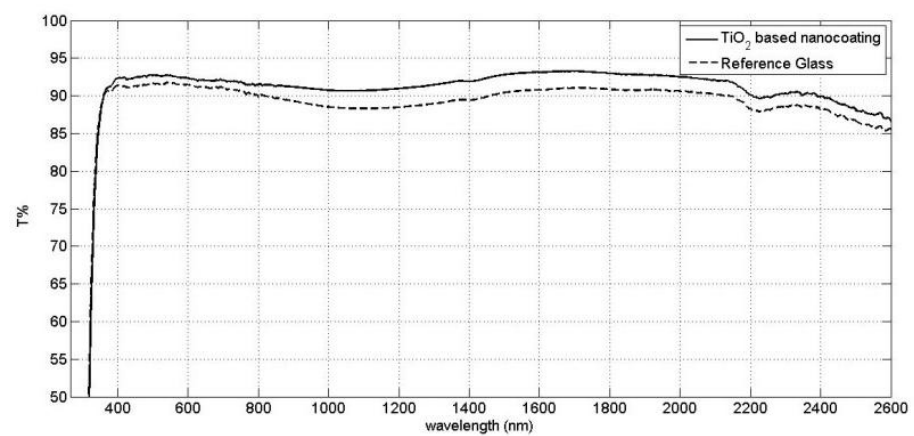

FIGURE 4. Spectral transmittance of $\mathrm{TiO}_{2}$ based nanocoating with self-cleaning properties and of reference glass.

In addition, coatings based on ITO nanoparticles were examined for use on glass parts of the IEB, with thickness of approximately 5-10 $\mu \mathrm{m}$. The sought Spectral Selective Properties, (SSP), of these nanocoatings were the low transmittance and high reflectance in the IR part of the solar radiation spectrum, as illustrated in Fig.5. The spectral transmittance and reflectance of such ITO coating samples on glass surface was measured using a UV-3600 Shimadzu spectrophotometer with MPC-3100 sample compartment and integrating sphere, and are presented in Fig.6. The one coating cuts off radiation at wavelengths above $1800 \mathrm{~nm}$ and the other at $2200 \mathrm{~nm}$. The transmittance of the samples at the solar region of the spectrum, was calculated based on the spectral transmittance weighted by the solar spectral distribution $E(\lambda)$, according to eq. 7 . The interval $\delta \lambda$ is considered $1 \mathrm{~nm}$, the wavelength range 300 $2500 \mathrm{~nm}$. The transmittance of the ITO coatings in the solar region was estimated 0.61 and 0.70 respectively.

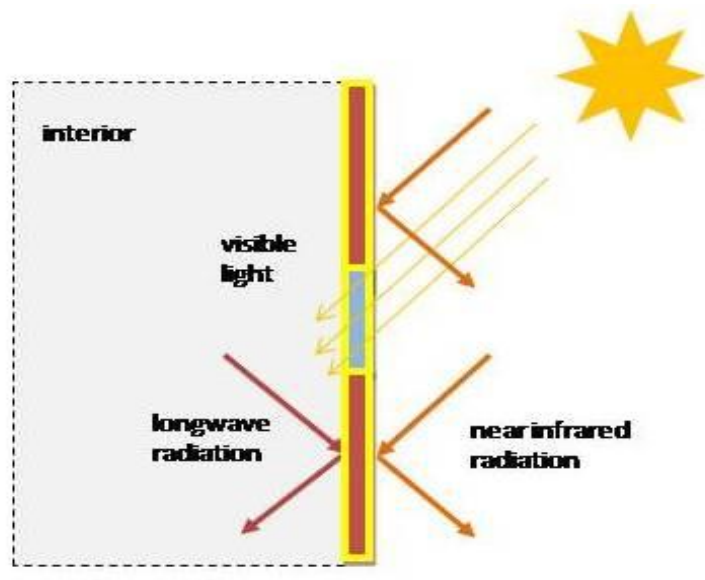

FIGURE 5. Spectral Selective Properties of the nano-coated surfaces in the IEB test cell. Low emissivity, $\varepsilon$, and high reflectivity, $r$, in the IR part of the solar spectrum. 


$$
\tau_{S O L}=\frac{\sum_{\lambda} \tau(\lambda) \cdot \mathrm{E}(\lambda) \cdot \delta \lambda}{\sum_{\lambda} \mathrm{E}(\lambda) \cdot \delta \lambda}
$$

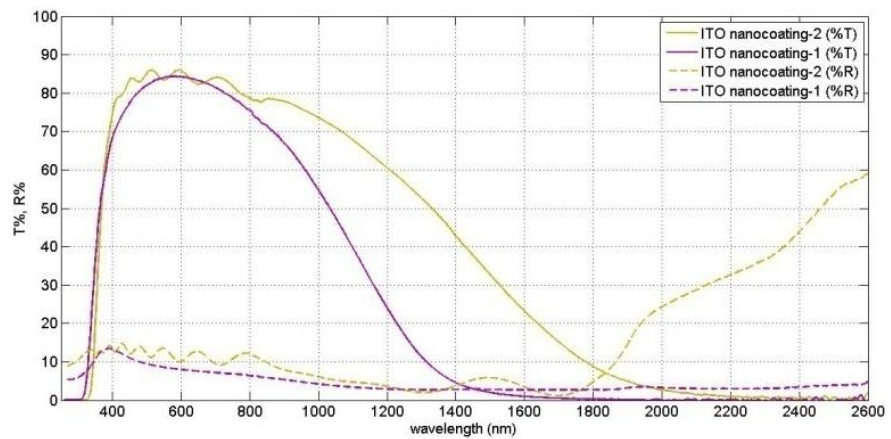

FIGURE 6. Spectral transmittance and reflectance of ITO based nanocoatings.

The contribution of the ITO coating increases further the thermal performance of the IEB pilot unit especially in summer time, where the room temperature was measured to be lower by $5-8^{\circ} \mathrm{C}$ than the one without nano-coated surfaces.

This ITO coating due to its thickness was not appropriate for PV glass cover. However, the samples tested on PV cells showed lower temperatures developed in the cell, causing a power recuperation of $+3 \%$ with reference to noncoated glass, which gives a promising property.

The IEB envelope according to the targets outlined above was re-evaluated and re-designed. Features like: innovative design of south walls with intelligent facades and window panes being coated with ultra thin films of nano-particles (ITO, $\mathrm{TiO}_{2}$ ) with optical properties as described, were embedded into its shell. All these according to the design and the add-on technologies made the building structure operate in pre-determined dynamic ways possessing a degree of intelligence.

\section{CONCLUSIONS}

The two IEB models designed, constructed and studied:

1.Have incorporated into their structures R.E.S. elements, like solar thermal and PV modules, new material and nano-coated surfaces with special SSP values to enhance building thermal performance in Winter and reduce cooling loads during Summer.

2.Experience natural ventilation induced by RES technics integrated on the roof, ending to a solar chimney

3.Have energy roofs and energy facades providing warm aqueous solution for under floor heating or space heating and domestic hot water

4. Behave appropriately as to meet cost-effectively the thermal/cooling, power loads by solar energy technologies

5. Predict the Power and Energy to be harvested hourly in a day, and hence

6. Manage the loads by time shifting according to the predicted power and energy

A total 30\% decrease of PV peak power is achieved based on the stochastic sizing and the nanocoatings, while in parallel the useful amount of thermal energy produced by the integration of RES into the envelope, covered the $60 \%$ of the thermal loads in January. All these provide a competitive and innovative intelligent building. The research is going on for examining the application of better SSP in nanocoatings.

\section{ACKNOWLEDGMENTS}

The authors acknowledge the Greek company NanoPhos for an ITO nanocoating, and thank Dr P. E. Barouchas and $\mathrm{Mr}$ A. Koulopoulos for support with the UV-Vis-NIR Spectrophotometer. 


\section{REFERENCES}

[1] R. Gicquel, P. Achard, European passive solar handbook: basic principles and concepts for passive solar architecture. Directorate-general for science, research and development, Commission of the European Communities, Brussels, 1986.

[2] A.K Athienitis, Thermal analysis and Design of Passive Solar Buildings, Ed. M. Santamouris, 2000.

[3] H. Lund, A. Marszal, P. Heiselberg. Zero energy buildings and mismatch compensation factors, Energy and Buildings 43, 1646-1654 (2011).

[4] Kolokotsa et al. A roadmap towards intelligent net zero- and positive-energy buildings, Solar Energy 85, 3067-3084 (2011).

[5] H. Doukas, et al. Intelligent building energy management system using rule sets. Building and Environment 42(10), 3562-3569 (2007).

[6] A. Hosein, G. Hoseini et al. The concept of zero energy intelligent buildings (ZEIB): A review of sustainable development for future cities. British Journal of Environment \& Climate Change 2(4), 339-367 (2012).

[7] A.J. Marszal, et al. Zero energy building: a review of definitions and calculation methodologies, Energy Build 43, 971-979 (2011).

[8] U. Desideri et al. Design of a multipurpose "zero energy consumption building" according to the European Directive 2010/31/EU, Architectural and Plant technical solutions, Energy 58, 157-167 (2013).

[9] S. Kaplanis, E. Kaplani, E.A. Daviskas, On the maximization of a cost-effective PV sizing; towards an intelligent building., Proc. Int. Conf. on Optimization of Electrical and Electronic Equipment (OPTIM), Brasov, Romania, 2008.

[10] S. Deng, R.Z. Wang, Y.I. Dai. How to evaluate performance of a net zero energy building-A literature research, Energy 71, 1-16 (2014).

[11] A. Mellit, M. Benghanem, S.A. Kalogirou. An adaptive wavelet-network model for forecasting daily total solar radiation, Applied Energy, 83, 705-722 (2006).

[12] S. Kaplanis, E. Kaplani. A model to predict expected mean and stochastic hourly global solar radiation I(h;nj) values, Renewable Energy 32, pp.1414-1425 (2007).

[13] E. Kaplani, S. Kaplanis, D. Panagiotaras, E. Stathatos, Optical Properties of ITO nano-coatings for Photovoltaic and Energy Building Applications. In 10th Int. Conf. of Computational Methods in Sciences and Engineering (ICCMSE), AIP Conference Proceedings 1618, Athens, 2014. p.348-353.

[14] S. Kaplanis, E. Kaplani, (Eds). Renewable Energy Systems: Theory, Innovations and Intelligent Applications, NOVA Science Publishers, N.Y., 2013.

[15] E. Kaplani, S. Kaplanis. A stochastic simulation model for reliable PV system sizing providing for solar radiation fluctuations, Applied Energy 97, 970-981 (2012).

[16] E. Kaplani. PV cell and module degradation, detection and diagnostics. In Proc. World Renewable Energy Congress (WREC XIII), London, 2014. 